\title{
ANATEXIA DE CROSTA INFERIOR E MÉDIA E GERAÇÃO DE GRANITOS NA NAPPE DE EMPURRÃO SOCORRO-GUAXUPÉ, SE DO BRASIL- UMA SÍNTESE PRELIMINAR
}

\author{
V.A.Janasi, A.C.B.C.Vasconcellos
}

\begin{abstract}
A Nappe de Empurrão Socorro-Guaxupé (NESG) ocorre como dois segmentos de crosta inferior a média que cavalgaram durante o ciclo Brasiliano rochas metassedimentares da Faixa Dobra Alto Rio Grande (extremo meridional do Cráton do São Francisco). Ambos os segmentos são constituidos por um cinturão granulítico basal que grada, a sul, para vários tipos de gnaisses migmatíticos; granitos ocorrem em abundância e variam amplamente em tipo e idade.
\end{abstract}

A associação granítica neoproterozóica mais antiga reconhecida na NESG forma batólitos alongados compostos por uma suite cálcio-alcalina potássica datada em $c a$. 650$640 \mathrm{Ma}$. Foi sucedida por uma suite mangerítica-granítica (a suite São José do Rio Pardo (SJRP) de Campos Neto et al., 1988) que forma corpos tabulares dobrados na porção central do segmento setentrional (a Nappe de Guaxupé, NG), recentemente datada em 630-625 Ma (U-Pb em zircão, Basei et al., 1995). Inúmeros pequenos corpos de granitos nebulíticos róseos, maciços a levemente foliados, equigranulares, intimamente associados a migmatitos (granitos tipos Pinhal e Nazaré Paulista) são intrusivos em ambas as associações acima. Após alçamento crustal significativo associado ao cavalgamento, esses terrenos de alto grau metamórfico foram invadidos pelos maciços graníticos de colocação rasa e caráter tardi-orogênico que constituem a Provincia Itu (610-580 Ma).

Estimativas das condições de pico durante o evento metamórfico principal que precedeu o cavalgamento indicam fortes gradientes, com $\mathrm{T}$ e especialmente $\mathrm{P}$ decaindo para sul, desde o cinturão granulítico basal, onde valores da ordem de $11 \mathrm{~kb} / 950^{\circ} \mathrm{C}$ são identificados, até as áreas migmatíticas, alcançando $\mathrm{P} \approx 4,5 \mathrm{~kb}$ e $\mathrm{T} \approx 750^{\circ} \mathrm{C}$ próximo a Atibaia, no segmento meridional (a Nappe de Socorro, NS) (Vasconcellos et al., 1991). A idade absoluta deste metamorfismo não foi determinada diretamente, mas está claramente confinada ao periodo 640$610 \mathrm{Ma}$, entre a colocação dos granitos cálcio-alcalinos potássicos (possivelmente de arco) e o desenvolvimento da Provincia Itu.

Fusão parcial ocorreu por toda a seç̧ão crustal ora exposta; variações significativas na composição dos protolitos e nos parâmetros intensivos (e.g., P,T, como referido acima) resultou na geração de uma diversidade de granitos crustais. Estes são aqui agrupados em duas associações principais (supersuítes?), cada uma delas passível de subdivisão em diferentes "tipos" de granitos.

A associação SJRP forma vários corpos tabulares dobrados, comumente zonados (mangerito cumulático basal gradando para granito fracionado de topo) que se concentram em uma faixa com extensão da ordem de $c a$. $100 \mathrm{~km}$ na porção central da NG, invadindo gnaisses migmatíticos metamorfisados a ca. $7 \mathrm{~kb} / 850^{\circ} \mathrm{C}$ (A.C. Vasconcellos, dados

DMP, Instituto de Geociências, Universidade de São Paulo. 
inéditos). Variações geográficas na química dos magmas parentais inferidos devem refletir fatores diversos, tais como diferenças nos protolitos, a incorporação eventual de um componente máfico (sugerida localmente pela presença de enclaves dioríticos e por $\mathbf{m g \#}$ mais altos), e variações nos parâmetros intensivos. Um tipo de rocha bastante peculiar, representado por charnoquitos finos volumetricamente pouco expressivos, distingue-se pela natureza extremamente empobrecida de seus magmas parentais, revelada por teores muito baixos de $\mathrm{Rb}$, Th e $\mathrm{H}_{2} \mathrm{O}$; anomalias fortemente positivas de Eu parecem refletir principalmente os baixos conteúdos de ETR trivalentes nesses magmas (Janasi, 1996).

A associação mangerito-granítica tem muitas semelhanças químicas com granitos "intra-placa" (baixo $\mathrm{mg \#}(=100 * \mathrm{Mg} /(\mathrm{Mg}+\mathrm{Fe}$ ), $10-20$; baixos $\mathrm{Ca}, \mathrm{Sr}$; alto $\mathrm{Zr}$, com freqüência acima de $1000 \mathrm{ppm}$ nos mangeritos menos fracionados). Esta química peculiar deve refletir a fusão parcial de granulitos empobrecidos sob condições de P e T anomalamente altas (respectivamente, $>10 \mathrm{~kb}$ e $\geq 950^{\circ} \mathrm{C}$; Janasi, 1996); essas condições são compativeis com aquelas identificadas nos granulitos basais da NG, que assim constituem fontes potenciais para os magmas quartzo mangeríticos (cf. Campos Neto et al., este volume).

Os granitos tipo Pinhal e Nazaré Paulista formam juntos a segunda associação, e correspondem a granitos migmatíticos diretamente relacionados a suas fontes, desde há muito reconhecidos como os produtos típicos da anatexia crustal na região (e.g., Wernick \& Penalva, 1980).

Os biotita granitos (tipo Pinhal) são predominantes na NG, onde com freqüência se associam a ortognaisses migmatizados que exibem leucossomas texturalmente similares a eles. Não existem estudos sistemáticos dedicados a esses granitos; em vista de sua natureza heterogênea, é incerto se os padrões inferidos a partir dos dados ora disponiveis podem ser extrapolados para toda a suíte. Comparados à associação SJRP, os granitos tipo Pinhal estudados são mais ricos em elementos radiogênicos, em particular $\mathrm{Rb}(c a .200 \mathrm{ppm})$ e Th (ca. $20 \mathrm{ppm}$ ), refletindo protolitos menos empobrecidos, e usualmente mostram maiores mg\# (20-30). Os conteúdos de $\mathrm{Zr}$, embora mais baixos que os das rochas da associação SJRP, são ainda elevados (usualmente, $400-600 \mathrm{ppm}$ ), revelando T liquidus em torno de $850^{\circ} \mathrm{C}$. Esta é uma temperatura típica do pico metamórfico em amplas porções da NG, possivelmente refletindo a extensiva fusão crustal associada à quebra de biotita em protolitos não-empobrecidos e conseqüente geração dos granitos tipo Pinhal. Relativamente baixa $\mathrm{a}\left(\mathrm{H}_{2} \mathrm{O}\right)(<<1,0)$ durante a anatexia é também refletida nas razões $\mathrm{K} / \mathrm{N}\left(\mathrm{mol} \mathrm{K}_{2} \mathrm{O} / \mathrm{Na}_{2} \mathrm{O}\right)$, que alcançam valores de até 1,31,5 na maior parte dos granitos tipo Pinhal.

Os granada-biotita granitos (tipo Nazaré Paulista) ocorrem principalmente nas porções médias a superiores da NS, onde vários tipos de metassedimentos portadores de granada são predominantes. Análises quimicas só existem para amostras das ocorrências mais meridionais (nas vizinhanças de Nazaré Paulista). Comparados aos granitos tipo Pinhal, esses granitos têm maior A/CNK (1,0-1,1) e mg\# (35-40), e menor Rb (130-150 ppm) e Zr (80-140 $\mathrm{ppm}$, correspondendo a temperaturas de saturação em $\mathrm{Zr}$ no intervalo $730-780^{\circ} \mathrm{C}$ ); $\mathrm{K} / \mathrm{N}$ são também usualmente mais baixos (em torno de 1,0 ), sugerindo geração sob a $\left(\mathrm{H}_{2} \mathrm{O}\right)$ levemente mais altas. Não existem até o momento análises de Th para essas rochas, mas mapas aerogamaespectrométricos sugerem que os granitos Nazaré Paulista concentram fortemente o Th em relação às suas fontes potenciais; a presença comum de monazita acessória também aponta para altos conteúdos de Th e ETRL nesses granitos.

No extremo sul da NS, onde predominam mica-xistos levemente ou nãomigmatizados, ocorrem alguns pequenos corpos de granito branco a duas micas (tgranada, turmalina) que representam os magmas crustais de temperatura mais baixa presentes na NESG. Esses granitos ainda pobremente conhecidos são petrograficamente similares a típicos granitos himalaianos "colisionais" que resultam da fusão de paragnaisses a baixas temperaturas 
$\left(650-700^{\circ} \mathrm{C}\right)$ através de reações de quebra de muscovita (e.g., Harris et al., 1995). Rochas similares são comuns invadindo metasedimentos de médio grau a sul da NESG; os escassos dados existentes para alguns desses maciços (Tico-Tico, Turvo) indicam uma posição estratigráfica similar (pós-magmatismo cálcio-alcalino potássico principal), e muitas das feições geoquímicas típicas dos chamados "leucogranitos colisionais" (Rb acima de $300 \mathrm{ppm}$, altos Cs, $\mathrm{U} / \mathrm{Th} ; \mathrm{Zr}$ muito baixo, usualmente $<50 \mathrm{ppm}$, indicando temperaturas de saturação inferiores a $\left.700^{\circ} \mathrm{C}\right)$.

O conjunto de dados existente sugere que um mesmo evento metamórfico regional foi responsável pela geração de uma ampla diversidade de granitos que seriam, se classificados através de diagramas de discriminação simplistas, considerados como indicadores de diferentes ambientes tectônicos. Ao invés disto, sugere-se que esta diversidade reflete primariamente variações nas composições dos protolitos e nos parâmetros intensivos. As idades absolutas dos vários tipos de granitos estão ainda por serem estabelecidas, mas devem ser bastante próximas, já que o evento que os gerou parece ter sido de curta duração (A.C. Vasconcellos, dados inéditos). Diferenças em idades relativas podem, no entanto, ser identificadas e potencialmente trazer informações bastante úteis: granitos tipo Pinhal fracamente deformados são com freqüência vistos invadindo mangeritos foliados da associação SJRP, o que implica que a fusão de ortognaisses não-empobrecidos de crosta intermediária ocorreu após a migração, colocação e deformação de fundidos derivados da crosta inferior empobrecida; uma anomalia térmica progressivamente ascendendo na crosta parece assim um requisito natural para quaisquer modelos tectônicos que sejam formulados para descrever o processo.

\section{Referências Bibliográficas}

BASEI, M.A.S.; SIGA JR., O.; SATO, K.; SPROESSER, W.M. (1995) A metodologia urânio chumbo na Universidade de São Paulo: princípios metodológicos, aplicações e resultados obtidos. Anais da Academia Brasileira de Ciências, v.67, n.2, p.221-237.

CAMPOS NETO, M.C.; FIGUEIREDO, M.C.H.; JANASI, V.A.; BASEI, M.A.S.; FRYER, B.J. (1988) The São José do Rio Pardo mangeritic-granitic suite, southeastern Brazil. Geochimica Brasiliensis, v.2, n.2, p.185-200.

CAMPOS NETO, M.C.; JANASI, V.A.; CABY, R. (1996) Ocorrência de granulitos empobrecidos nas porções basais da Nappe de Empurrão Socorro-Guaxupé. Boletim IGUSP (este volume).

HARRIS, N.; AYRES, M.; MASSEY, J. (1995) Geochemistry of melts produced during the incongruent melting of muscovite: Implications for the extraction of Himalayan leucogranite magmas. Journal of Geophysical Research, v.100, n.B.8, p.15767-15777.

JANASI, V.A. (no prelo) Neoproterozoic mangerite-granite magmatism in southeastern Brazil: the São Pedro de Caldas massif. Anais da Academia Brasileira de Ciências.

VASCONCELLOS, A.C.B.C.; HARRIS, N.B.W.; TINDLE, A.G. (1991) The relationship between metamorphism and tectonics: evidence from the Socorro-Guaxupé thrust nappe, southeastern Brazil. In: TUISKU, P.; LAAJOKI, K. (Eds.) Metamorphism, deformation and structure of the crust. Oulu, The University of Oulu, p.86.

WERNICK, E.; PENALVA, F. (1980) Contribuição à geologia do Grupo Pinhal (SP e MG). Revista Brasileira de Geociências, v.10, n.1, p.43-62. 